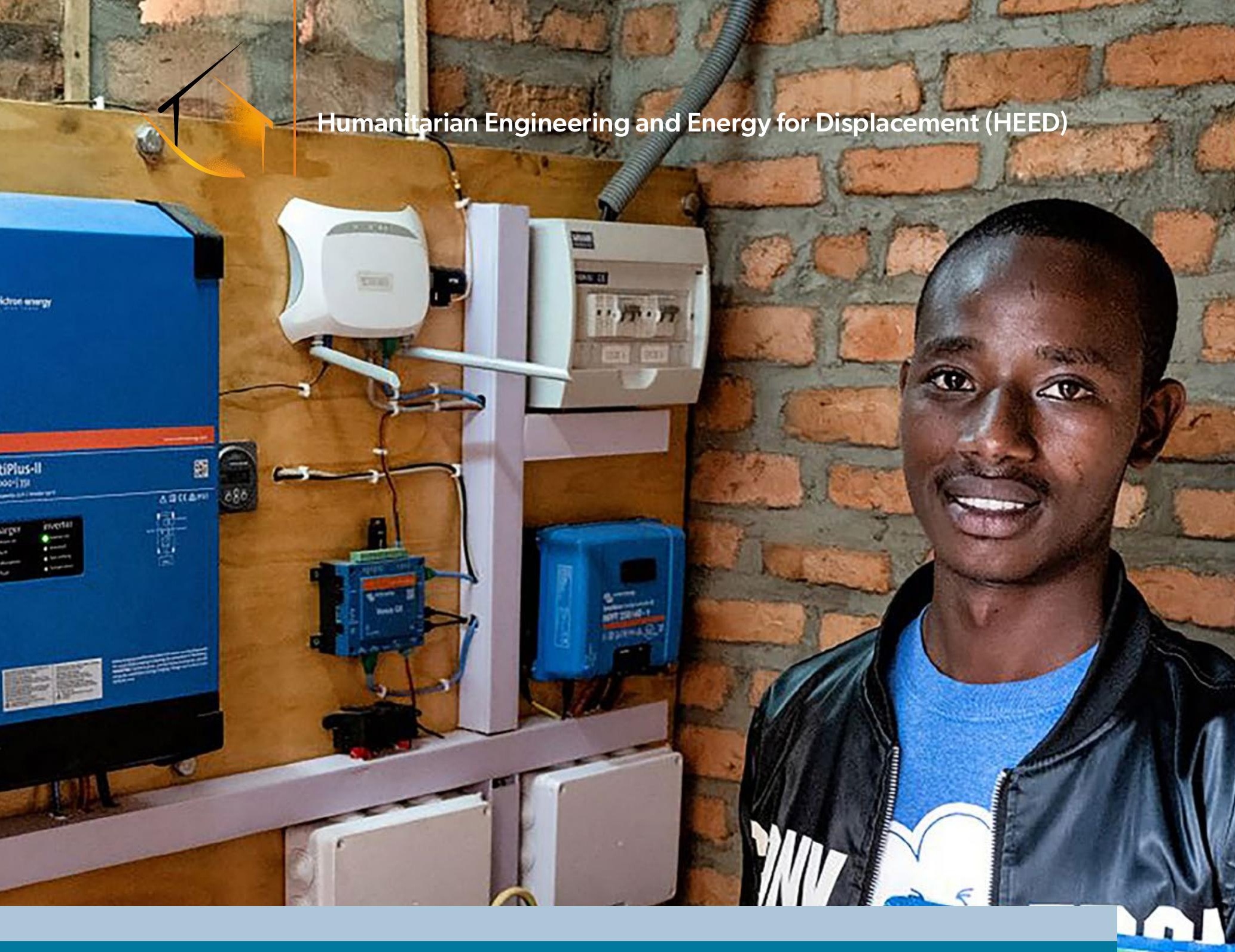

\title{
Building capacity: HEED skills audit and recommendations
}

Alison Halford | March 2021

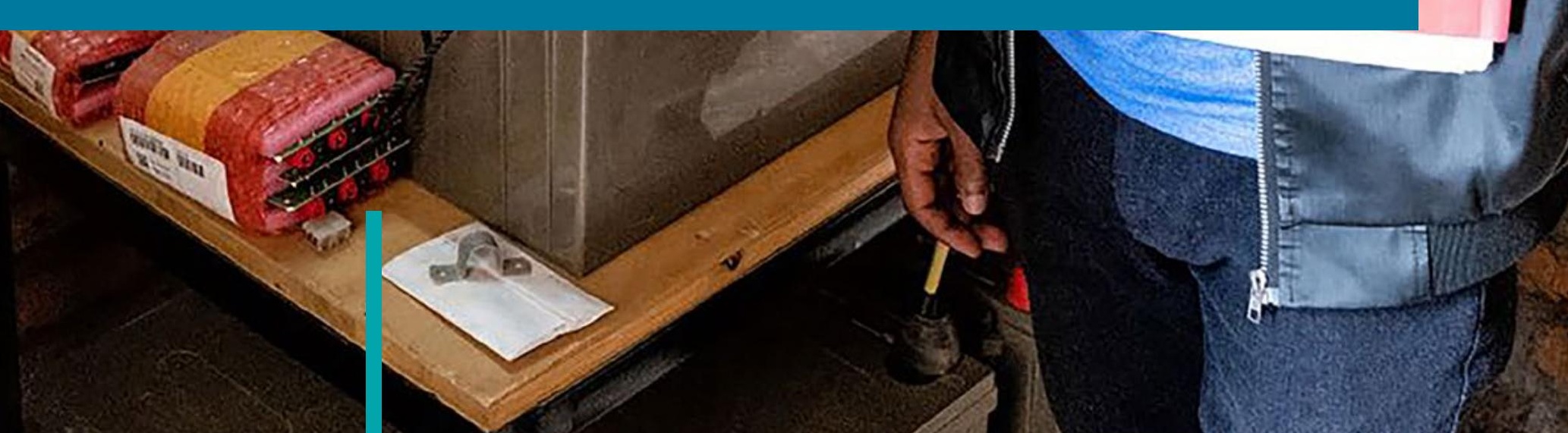




\section{Acknowledgements}

The author would like to acknowledge the financial support of the Engineering and Physical Science Research Council (EPSRC) for funding the Humanitarian Engineering and Energy for Displacement (HEED) project as part of the Global Challenges Research Fund (EP/P029531/1). The authors would like to acknowledge and thank project delivery partners Practical Action and Scene Connect for their significant role in co-ordinating in-camp activities and providing technical inputs and tools. We would also like to recognise the support of MIDIMAR (Ministry of Disaster Management and Refugees) and UNHCR (United Nations High Commissioner for Refugees) and the contributions of the Global Plan of Action, Chatham House, and the RE4R (Renewable Energy for Refugees) Project (a partnership between Practical Action and UNHCR, supported by the IKEA Foundation).

Special thanks go to Professor Elena Gaura for her valuable feedback and Hajar Al Kaddo for reviewing this report. The author would like to especially thank Berthille Kampire, Dr Jonathan Nixon, Evariste Muhire, Milan Joshi, Theogene Ndatimana, Sandy Robinson, and Melania Tarquino for sharing their insights on their learning journey, without which this report would not be possible.

\section{Authors}

- Alison Halford

More details on the HEED project can found at http://heed-refugee.coventry.ac.uk

Photo credit: CHEED, CEdoardo Santangelo, Coventry University

The HEED project is funded by the Engineering and Physical Science Research Council (EPSRC) as part of the Global Challenges Research Fund. HEED is led by an interdisciplinary team based at Coventry University, in partnership with the international development charity, Practical Action, and Scene Connect, a social enterprise strengthening communities through the development of ICT products.

This report should be referenced as:

Halford, A. 2021. Building capacity: HEED skills audit and recommendations.

Humanitarian Engineering and Energy for Displacement (HEED) Project, Coventry

University. DOI: 10.18552/HEED/2021/0002

Cover: Micro-grid Supervisor. Jean is responsible for managing and supervising the solar PV micro-grid that supplies electricity to three communal buildings: one playground and two nurseries. Nyabiheke, Rwanda. 


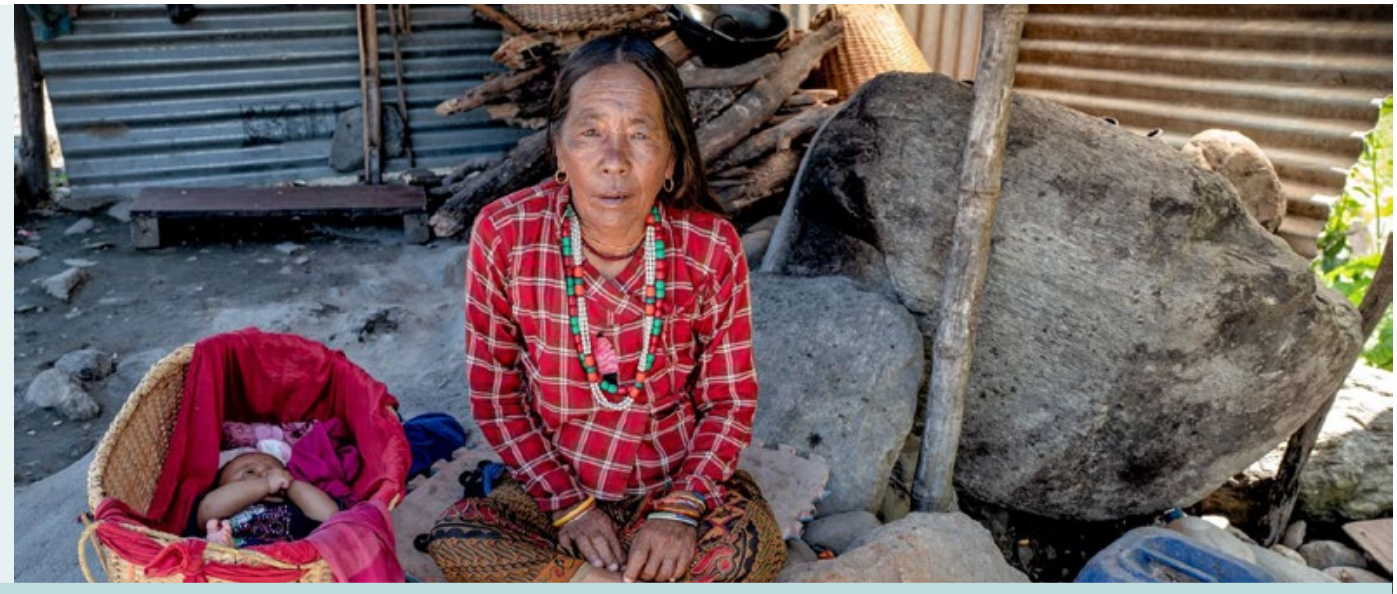

\section{Contents}

Foreword

Aims and purpose

Overview of recommendations

Delivering impact around capacity building: Theory of Change

Recommendations

Concluding reflections

HEED team and project partners 


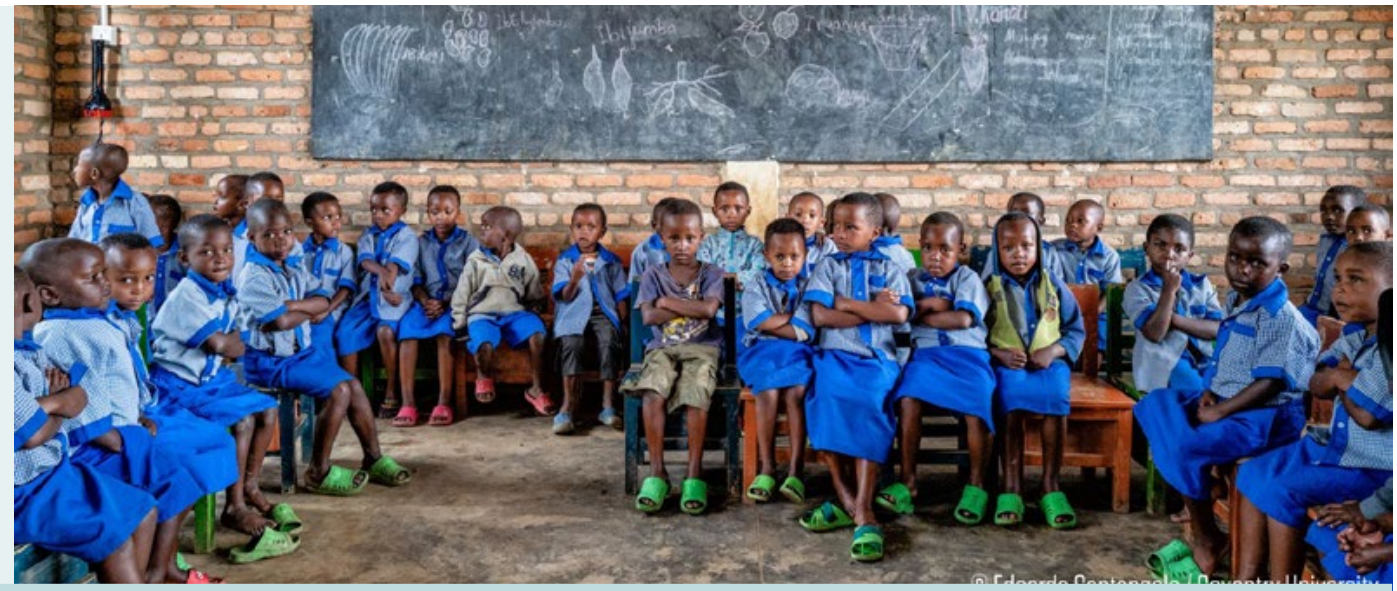

\section{Foreword}

Reflecting on my experience as a team leader and principal investigator on the project, I believe HEED gave us a unique opportunity to do 'energy in protracted settings' differently. As a scientist, HEED offered more than anything else the chance to look at the role of science through a different lens, that is through the eyes of the communities. Throughout the project I felt empowered - supported by the ability and capacity of the project and its emerging science to 'do good', but I also felt enormously humbled, realising how much we don't know, how many answers we don't really have and how much those answers are needed now.

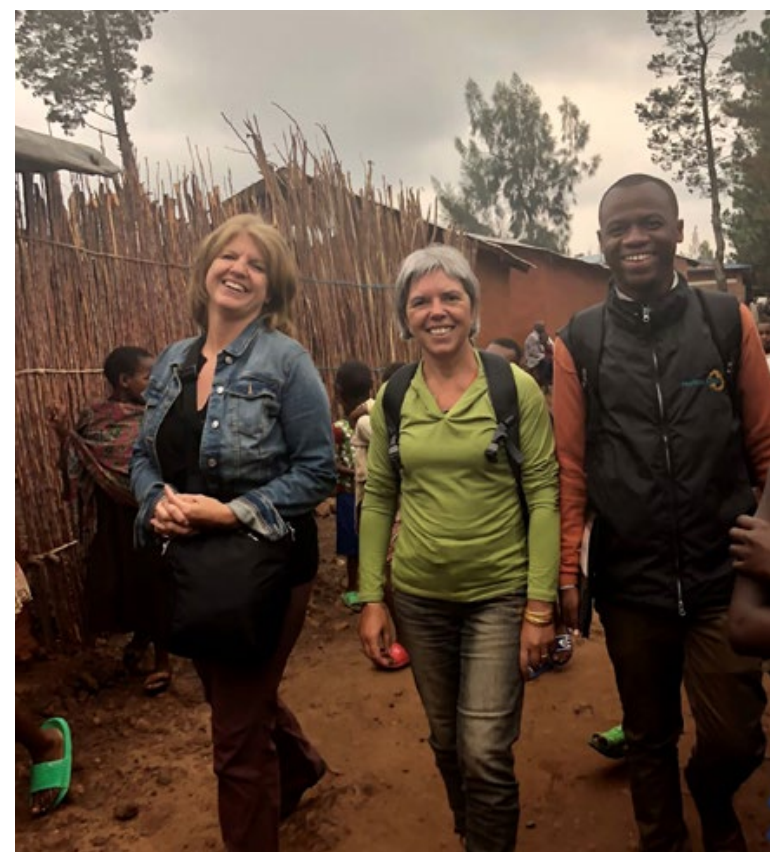

The project offered all parties involved (researchers, contractors, refugees and practitioners) an opportunity to effect a shift in the way they work, think, conduct their business, see a purpose, use tools and look to the future. All of this was achieved through partnership and by forming a very close-knit team throughout the project lifetime to carry it through; without teamwork, we would not have succeeded. I am clear, for example, that my definition of 'best science' shifted to become 'best that I can explain, put to use and make a difference with'.

Photo: Professor Heaven Crawley and Professor Elena Gaura (HEED) and Jean- Claude Nshimiyimana (Practical Action) Kigeme, Rwanda, 2018 
Moving forward in my research, I bring a new understanding of how diverse teams take diverse approaches, which enriches a project's impact. I now see co-designing with communities as a three-stage process: listen, learn and only then act. I see that communication challenges are rarely only about language - they are shaped by the frameworks we think and work within.

Being pushed out daily from my comfort zone by the project and its team has been the most enriching experience of my career so far. I hope that sharing the experiential stories of working with communities in four refugee/IDP camps in two countries will be of use to other teams when implementing energy projects in the displaced setting. We are, in HEED, an interdisciplinary team with multiply partners, all with different expectations and approaches to what makes a sustainable, resilient energy solution for refugees.

By working together to understand how energy systems are best designed and implemented, owned and sustained by those

they deliver energy to, placing the people at the centre, we are hopefully building a legacy of learning that will serve the purpose we set to achieve so many months ago.

Professor Elena Gaura

HEED Principal Investigator ]

Professor of Pervasive Computing

Coventry University 


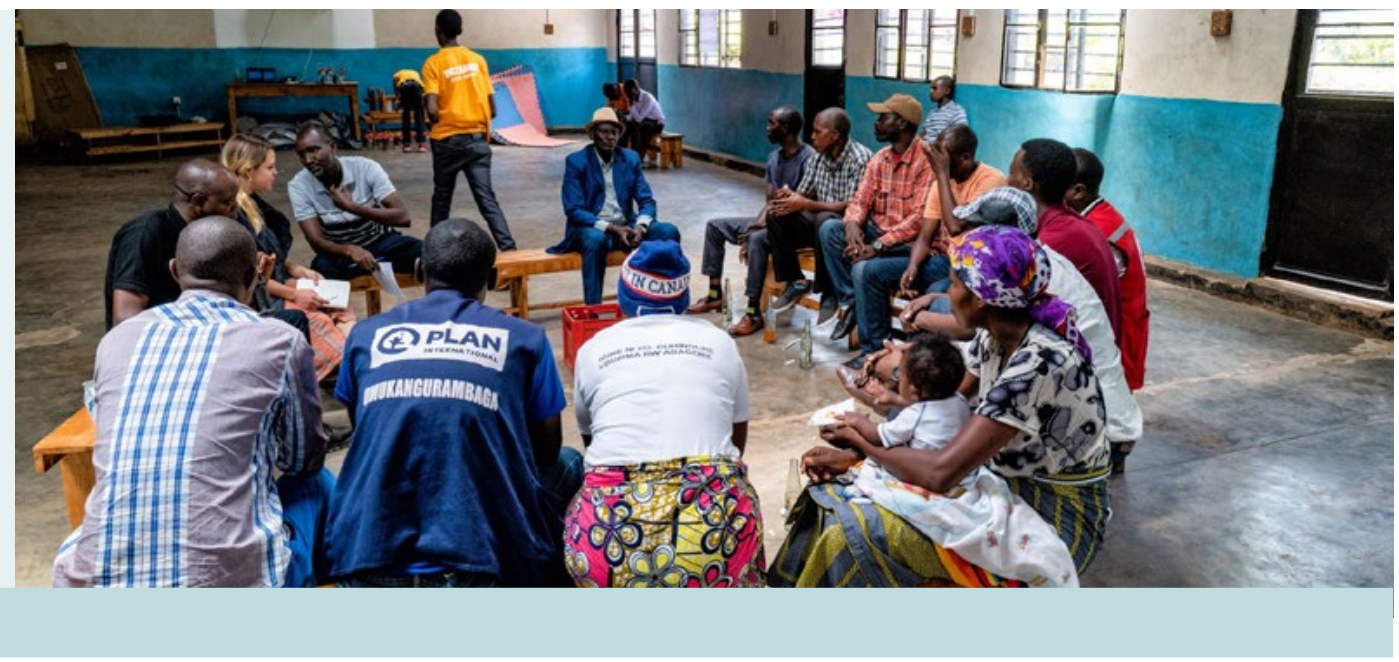

\section{Aims and purpose}

HEED's overarching mission was to understand the energy needs and aspirations of forcibly displaced people to improve access to safe, sustainable and affordable energy services. To design energy interventions that produce outcomes to achieve impact, we propose the salience of skills development must be evidential at every stage of an energy research project. HEED, therefore, sought impact through activities around the following three areas:

- Instrumental: In what ways is HEED influencing policy, practice or service provision in the delivery of energy to displaced people?

- Conceptual: How is HEED contributing to a greater understanding of issues and reframing debates in the field of humanitarian energy and engineering?

- Capacity building: To what extent is the HEED project developing technical and personal skill-sets that increase self-reliance, self-determination and autonomy?

This report aims to explore how HEED approached and delivered capacity building for the research team, project partners and the communities the team worked with in Rwanda and Nepal.' This report's purpose is threefold: first, to be evidential on how HEED planned, delivered and captured impact around capacity building so similar projects can develop best practice when skills development is a key deliverable. Second, to encourage other energy projects to document the impact produced by researchers and practitioners' involvement while working with communities. Therefore, to recognise the tacit and dynamic aspects of knowledge production, not only the more explicit aspects. Third, suggest recommendations to support a skills-led approach to capacity building that provides personal and professional development opportunities to deepen knowledge production and impact.

1 In this report when we reference community, we are referring to a particular group or groups within a locality. 


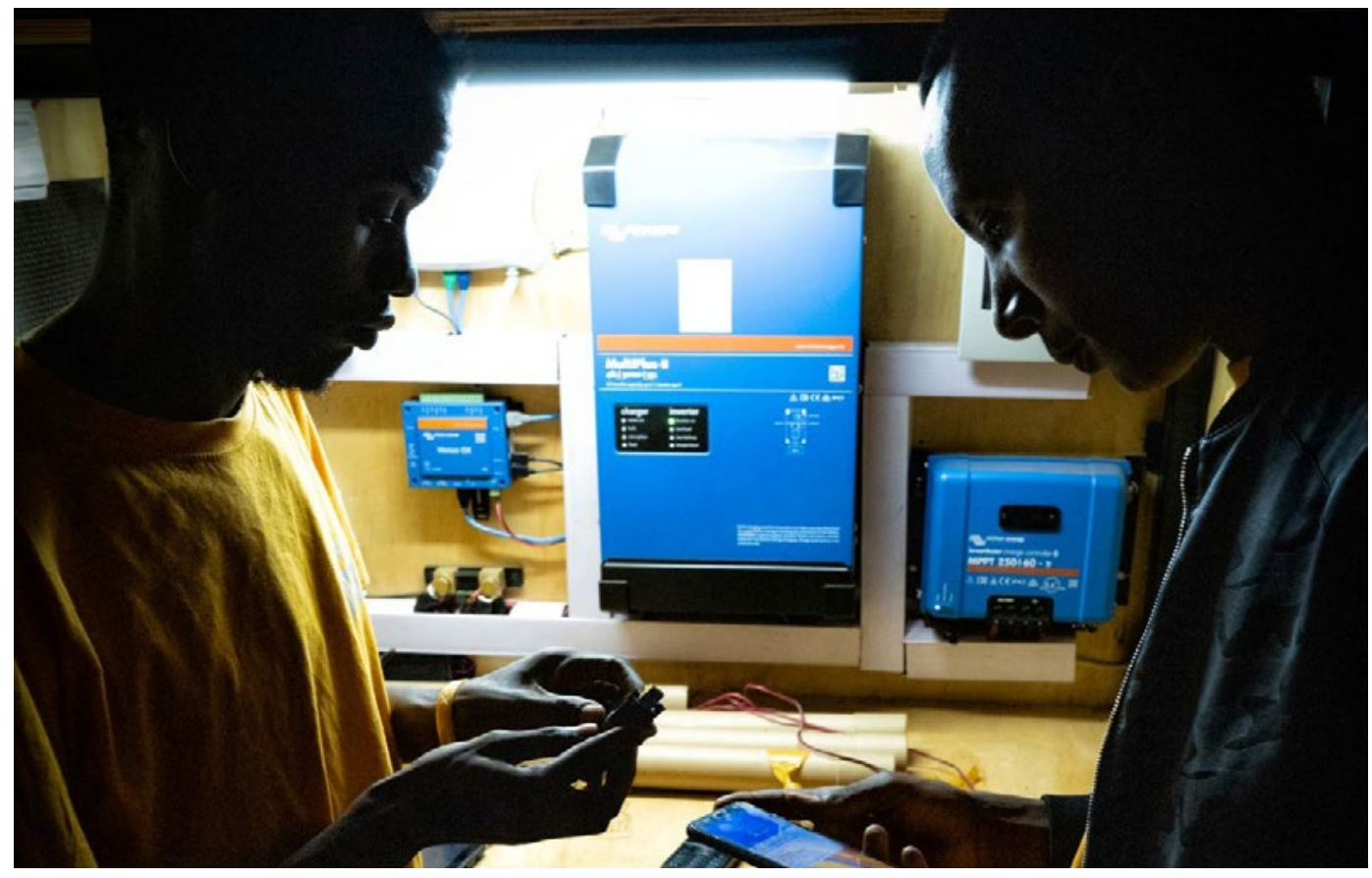

The examples presented in this report highlight outputs that offer opportunities for skills development that can be transformative to people's lives. We recognise that attempting to formulate programmes that improve communities' skills in displacement settings pose a number of challenges, not least issues around refugees' right to work and freely move between camps and host communities (Easton-Calabri and Omata, 2018). Without stakeholders, such as host governments, donors, development agencies, international agencies such as UNHCR and other relief organisations, implementing policies that allow freedom of movement, camp-based refugees will continue to be limited in gaining economic opportunities, which ultimately will impact the well-being and life prospects of these communities. Nevertheless, prioritising skills development as a key outcome helped focus the attention of this report on how the project could assist in capacity building of refugee and IDP ${ }^{2}$ communities to support the sustainability of energy interventions. Simultaneously, the project found that documenting the impact of involvement upon the HEED team was beneficial as it gave insights into how their own personal and professional capacity and capabilities developed during the project's lifetime.

\section{Project background}

Over the past three years, the Humanitarian Engineering and Energy for Displacement (HEED), an interdisciplinary team based at Coventry University, in partnership with the international development charity Practical Action and Scene Connect, have been working to develop innovative responses that improve energy services in displacement settings. The project worked with Congolese refugees in three camps in Rwanda (Gihembe, Kigeme, and Nyabiheke) and IDPs in Nepal to understand energy usage in refugee camps and settlements.

2 Internally displaced persons (IDPs). 
With an estimated 7 million displaced populations in camps having access to electricity for less than four hours a day, refugees and displaced people are among the most likely groups left behind in the global drive for energy access (Lehne et al, 2016). Solutions are required to ensure inclusive, affordable, and sustainable energy systems to meet Sustainable Development Goal 7 ('affordable, reliable, sustainable and modern energy for all') (Lahn \& Grafham, (2015). However, technological innovation driven solutions are not sufficient. The existing approach to energy access will continue to embed aid dependence unless the energy interventions i) build technological skills, ii) draw upon local resources, and iii) open up a range of community ownership models. Moreover, without evidential data on these and other alternative approaches to energy interventions, practitioners, policymakers, and energy stakeholders will lack appropriate guidance on implementing flexible and responsive systems to rapid changes in community needs.

HEED explored the potential of alternative energy ownership models informed by sensor data and using renewable technologies. The first stage of the project was to collect data using sensors and surveys on existing energy provision and the energy needs and aspirations of refugees. After numerous community consultations between HEED and energy stakeholders in Rwanda and Nepal, HEED implemented a series of interventions that included sensors to provide data. In Nepal, the sensors in footfall monitors and individual energy appliance monitors documented electricity usage, costs, and sufficiency in grid-connected sub-metered scenarios.

\section{People who have worked on HEED}

September 2017 î September 2020

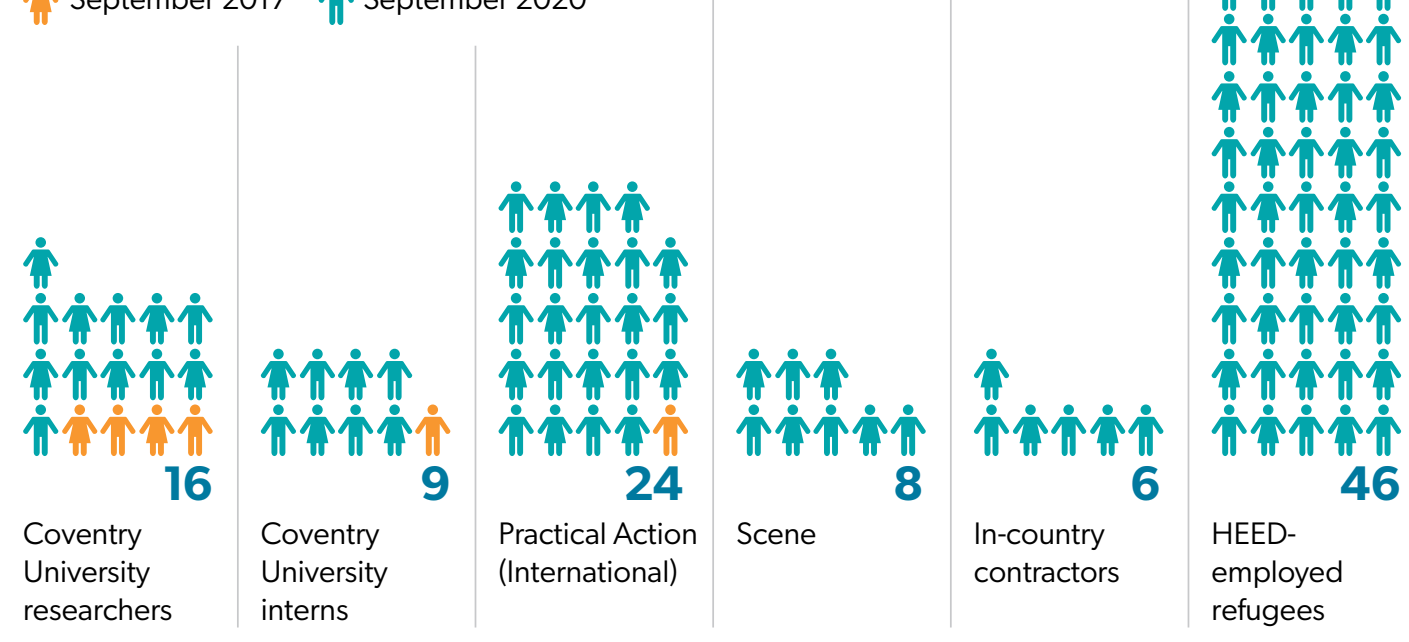

In Rwanda, sensors collected data on cookstoves, solar mobile lanterns, and communal lighting. In addition, over 1,000 survey responses collected, which helped identify what skills the community could offer for maintenance and their expectations of the long-term sustainability of interventions.

The next stage of the project saw HEED deliver a series of workshops, which offered individuals and community leaders the opportunity to develop energy protocols that respond and embed the lived experience in the displacement setting. These sessions included resolving issues of liability before deploying interventions - such as a duty of care for the systems, identifying stakeholders and feasibility of multi-tiered ownership. 
HEED also shared sensor findings with the community as transparency around energy usage is an important aspect of HEED's energy design protocols. Energy data in the hands of the community can assist in managing expectations on how the interventions will be used and encourage communities to think about ways to use surplus energy. As the development of skills was integral to the project outcomes, there was discussion around how to support camp residents to accomplish certain project tasks during the workshops. Therefore, before the interventions were deployed, HEED employed camp-based refugees (Rwanda) and IDPS (Nepal) as community mobilisers to provide simple repairs and advice to end-users on the energy interventions.

The final stage of the project was the piloting of community co-designed solar interventions. In Khalte, Nepal, the interventions were seven advanced solar streetlights, which were handed over to the community in December 2020. In Rwanda, HEED installed a standalone solar system for a community hall and 40 solar mobile lanterns in Nyabiheke; a PV-battery micro-grid for two nursery buildings and a playground in Kigeme; 8 solar street lights and four advanced solar street lights in Gihembe. The interventions were handed over to Alight and World Vision in January 2021 but are still managed by the community leaders. Subsequently, six refugees were hired as in-camp technicians to provide ongoing maintenance after the project ended. Solar energy supplier Mesh Power delivered a full training and skills development programme, which furthered their skills, and they also received tools and earned certification on the skills developed.

Over half the people HEED employed over the project lifetime were displaced people: 34 refugees as security guards, enumerators (who collected survey data) and community mobilisers in Rwanda, and in Nepal, 11 internally displaced people as enumerators and community mobilisers 


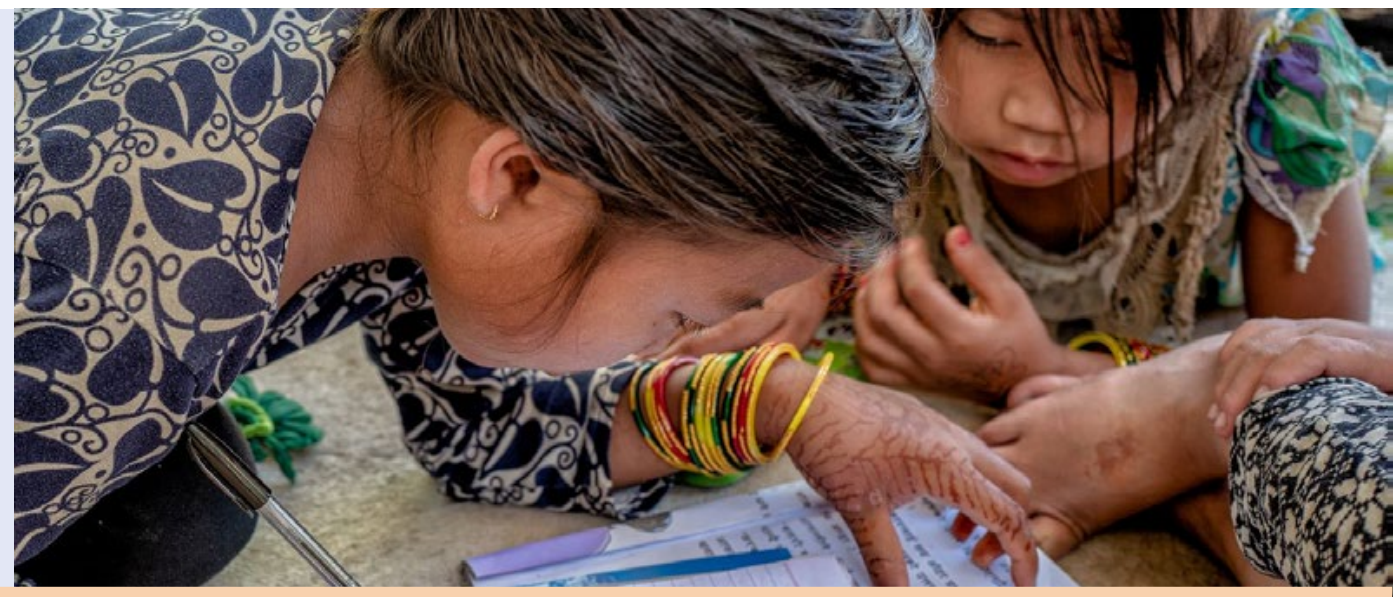

\section{Overview of recommendations}

The recommendations draw upon case studies to provide insights into integrating skills development (as a significant outcome) and impact when designing and deploying energy systems in the displacement context. By identifying what skills are required to improve a project's sustainability and promote positive engagement, these recommendations could aid project planning around capacity building in other energy research projects.

\section{Build lines of communication between stakeholders around energy needs and} aspirations as part of the design process, not separate from it. Engaging a range of energy stakeholders at the local level through appropriate discussions before designing and implementing a project will create more holistic energy interventions. Understanding what refugees and IDP's see as the energy market needs also avoids culturally inappropriate solutions or imposing a blanket or single solution in all contexts.

\section{Socio-technical solutions need to emerge from conversations with refugees,} IDPs, practitioners and other energy stakeholders. Funding alone for technological innovation-driven solutions is not sufficient to produce robust energy eco-systems in the displaced context. The existing approach to energy access will continue to embed aid dependence unless the energy interventions i) build technological skills, ii) draw upon local resources, and iii) open up a range of community ownership models.

\section{Adopt a skills-based approach to improve energy access in the displaced setting.}

The UNHCR 2017-21 strategic plan seeks to 'ensure that they are equipped with relevant skills and capacities in locations of displacement and promote access to education and livelihoods to improve self-reliance and support solutions' (UNHCR, 2017). Although political and economic constraints may limit possibilities, energy projects that include ways to develop and build forcibly displaced people's skills in delivering, improving, and maintaining energy systems open up space for camp-based refugees and IDPs to be users and producers of energy. 


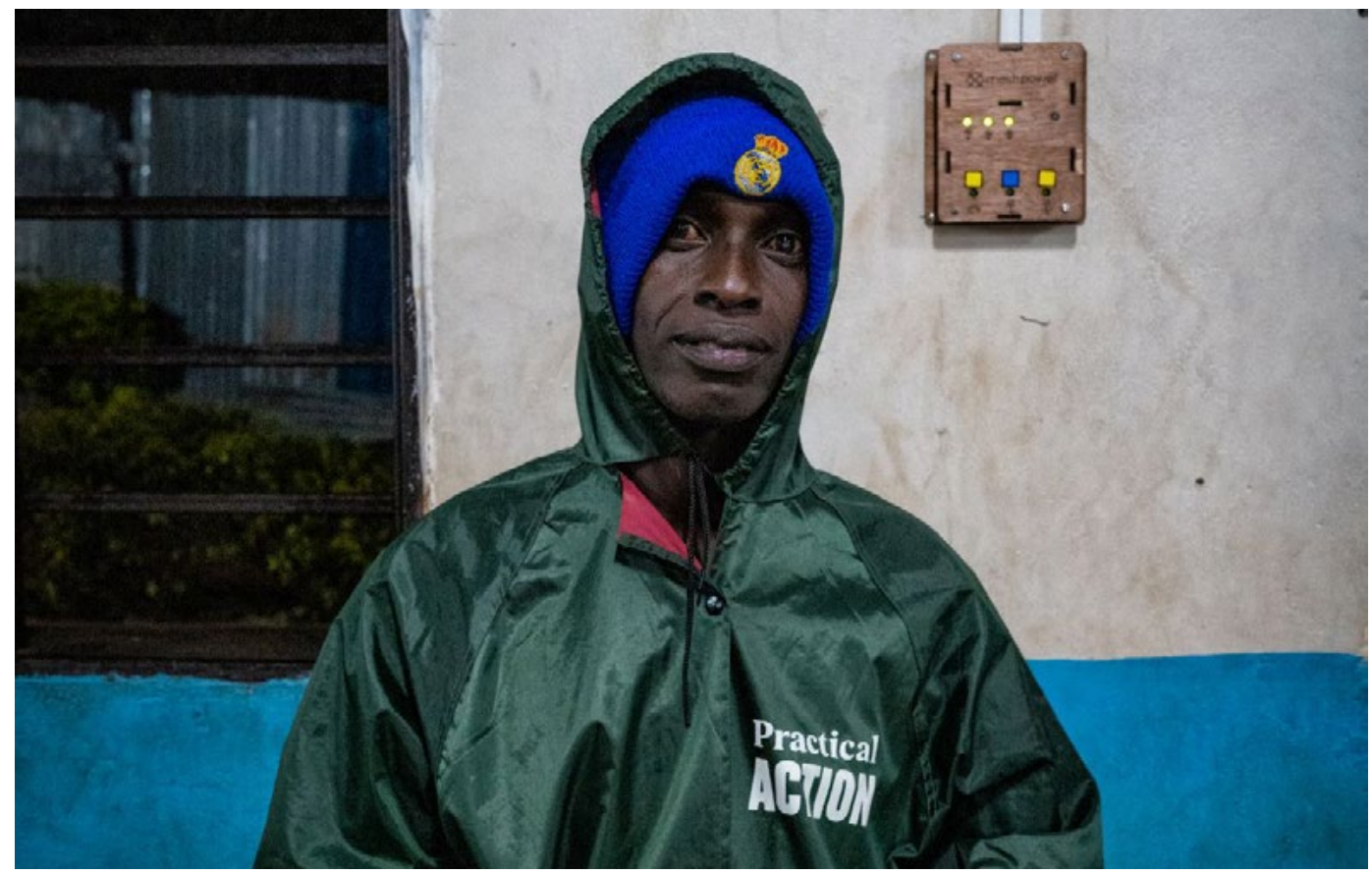

4. Plan opportunities within the project for communities to gain skills during the design and production phases to support the sustainability of renewable energy interventions. Before implementing a project, consider the extent to which certain tasks can be accomplished by camp residence. For instance, if there is a skills gap, explore existing avenues to support upskilling and training that can contribute to the longevity of the energy installations. In tandem with the right to work, these skills may become transferable in other employment settings. As they gain experiences working with new technologies, these skills could improve camp-based refugees' self-reliance.

\section{Acknowledge how project involvement is transformative personally and} professionally for those working on the project. Documenting the impact of involvement in research projects often equates to demonstrating tangible, measurable outputs at the expense of more abstract and less instrumental achievements. Marginalising the emotional impact of research involvement fails to recognise the way the experience of working on a project can have an impact in profound and sometimes life-changing ways for individuals.

6. Recognise and record the teams 'learning journey' as an impact of the project. Be evidential about the extent to which the project aims can support and strengthen the project team's skills and abilities. Reflectivity on the positive impact of project involvement on both individual and team well-being builds capacity and resilience resulting in multiple beneficiaries of projects at differing levels of responsibility and roles. 


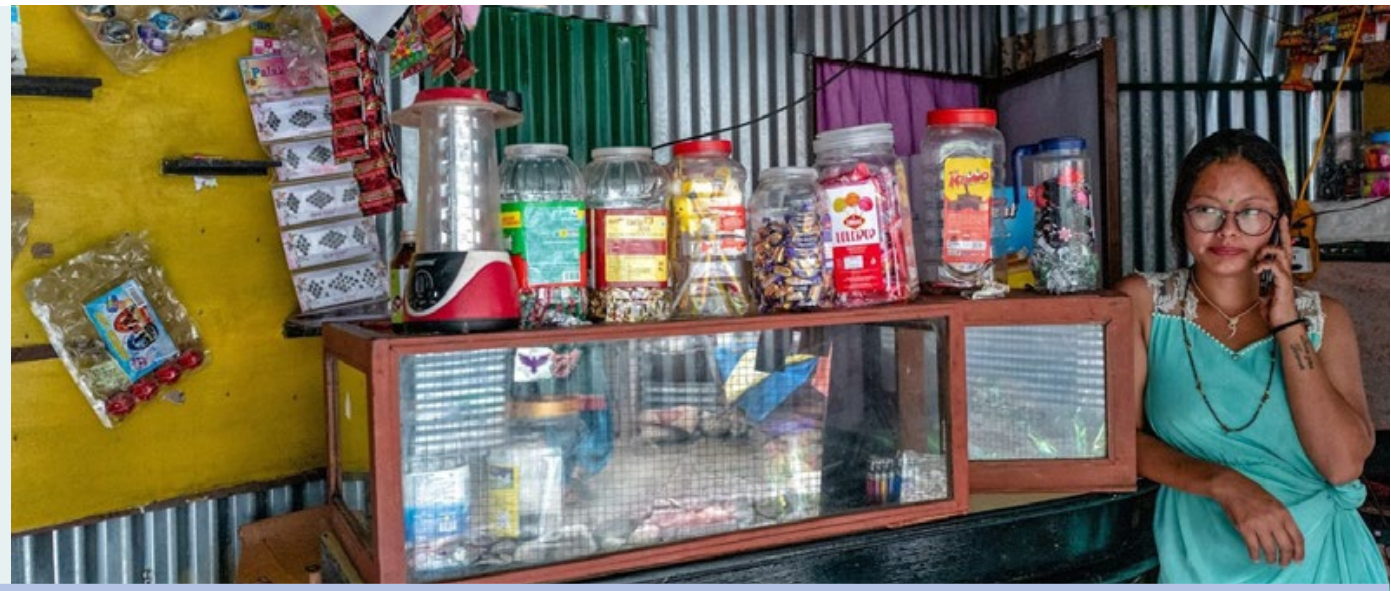

\section{Delivering impact around capacity building: Theory of Change}

Impact is about the transformation of project objectives into demonstrable actions. HEED approached impact through 'Theory of Change', which allowed the project to 'not only to do good but, perhaps more important, to understand how, when, and why the good is being done'. (Weiss, 1995: 90)

\section{Theory of Change}

\begin{tabular}{|c|c|c|c|c|}
\hline $\begin{array}{l}\text { Research funding } \\
\text { Researchers } \\
\text { Existing } \\
\text { knowledge } \\
\text { Facilities \& } \\
\text { equipment }\end{array}$ & $\begin{array}{l}\text { Research \& } \\
\text { development } \\
\text { New methods } \\
\text { Collaboration } \\
\text { Experimentation } \\
\text { Theorising }\end{array}$ & $\begin{array}{l}\text { Publications, } \\
\text { datasets \& } \\
\text { products } \\
\text { Innovations: } \\
\text { Methods \& } \\
\text { processes } \\
\text { Community } \\
\text { engagement }\end{array}$ & $\begin{array}{l}\text { Cited outputs } \\
\text { Uptake of tools \& } \\
\text { instruments } \\
\text { Skills } \\
\text { development } \\
\text { Policy changes }\end{array}$ & $\begin{array}{l}\text { Economy } \\
\text { Society } \\
\text { Education } \\
\text { Health \& wellbeing } \\
\text { Environment }\end{array}$ \\
\hline Inputs & Activities & Outputs & Outcomes & Impact \\
\hline
\end{tabular}

Theory of Change starts with project impact and outcomes and then maps backwards, working through the intermediate - activities and outputs - and finishes with the project funding and aims. Understanding first the final project outcomes shifts away from the more conventional 'so-that' approach, which sees a project begin with an intervention 'so that' action happens and consequently, 'so that' aims are achieved (Taplin et al,2013). Theory of Change as a planning tool explicitly articulates the causal pathway that will lead to the end goal, identifying strategic interventions that will result in the desired change, the added value of the interventions and progress indicators. 


\section{Case study: Energy 'designathons'}

\section{Design for displacement (D4D) and Energy for end users (E4E) workshops}

One outcome of the project was to conceptualise an energy design protocol that positioned refugees and IDPs centrally in the decision-making on energy interventions in camps. Using the Theory of Change by mapping backwards, HEED considered the factors, barriers, and practices instrumental in limiting and/or improving the delivery of modern, affordable, and renewable energy to displaced people. The project then conceived a narrative around the logic of the interventions, which identified three 'pathways of change'- a set of connected outcomes that could track the projects progress and scale of impact: ${ }^{3}$

- Improved knowledge - What skills were needed by HEED to produce new knowledge on the use of data, sensors, the Internet of Things and energy systems in the displacement setting?

- Increased opportunities - In what ways did HEED address gaps in skills that supported economic growth, greater employment and career progression?

- Life experiences - How did people's involvement with the project alter perspectives, practices and knowledge?

Planned activities, therefore, were connected to outputs, outcomes and impact around capacity building in a way that could be shared and engaged by both those internal and external to the project. The 'designathons' activities, for example, were a significant factor in generating outputs and outcomes that demonstrated the potential of community co-designing to improve access to sustainable and resilient energy for refugees and IDPs (Demir, 2020). The designathons were delivered in two stages; the first series of workshops was 'Design for Displacement (D4D)' designathons hosted in the UK, Nepal, and Rwanda. The D4Ds connected academics, NGOs, energy actors and service providers to discuss best practice in developing design for energy and engage delegates in wider debates on energy inequality and poverty. These workshops developed energy protocols that sought to address the lack of data on energy usage, the role of research in providing energy solutions that embed refugees and displaced people in the decision-making process and the importance of acknowledging contexts when designing energy policies and services.

The second series of workshops were twelve 'Energy for End Users' (E4E) workshops: nine in Rwanda and three in Nepal. These events brought together key user groups of the proposed energy interventions from the camps, including young people, women, social entrepreneurs, local business owners and community leaders with the HEED team to formulate an E4E protocol. The resulting E4E protocols emerged from refugees and IDPs' lived experiences, which worked towards addressing key issues around energy needs and aspirations, community ownership, and sustainability. The protocols coalesce with literature that contends similar participatory approaches when collecting data will help deliver energy solutions that reflect refugee and IDPs needs and aspirations (Demir, 2020; Rosenberg-Jansen, 2020).

3 Ibid vii pl. 


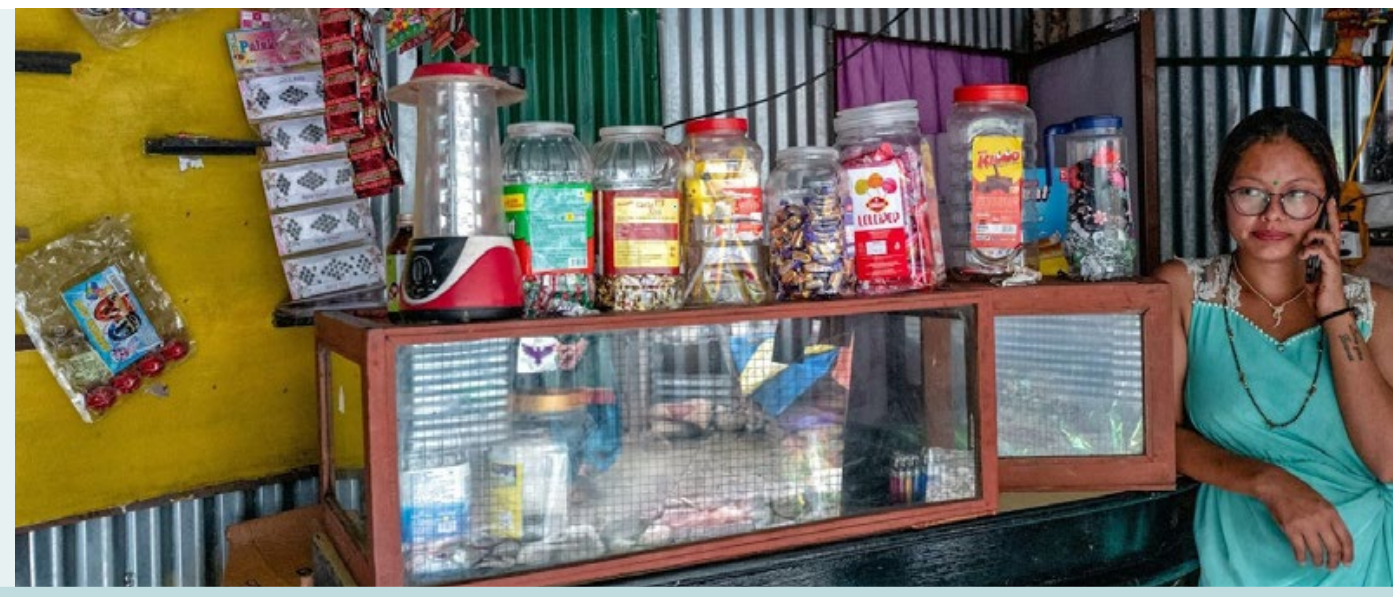

\section{Recommendations}

\section{Skills development recommendation 1}

Improved Knowledge - What skills were needed by HEED to produce new knowledge on the use of data, sensors, the Internet of Things and energy systems in the displacement setting?

i. Build lines of communication between stakeholders around energy needs and aspirations as part of the design process, not separate from it. Co-producing knowledge with communities regarding energy provides insights into complex social locations bound to a socio-historical context and addresses power asymmetries in the research process. Privilege is indexed when speaking for and about a group, particularly marginalised communities. Irrespective of the well-meaning intention, if the social location of a speaker is perceived as more authoritative than those they are speaking for, their voice will overwhelm those they claim to represent (Alcoff, 2009).

ii. Socio-technical solutions need to emerge from conversations with refugees, IDPs, practitioners and other energy stakeholders rather than imposed by the project onto displaced communities. There are increasing calls from humanitarian energy actors to embed communities in the design and implementation phases (Rosenberg-Jansen, 2020). Therefore, a projects ability to connect with communities during every project phase makes it essential to continue discussions during a project's lifetime, rather than only at the start and/or end of the project.

Photo: Khalte, Nepal, 2019 


\section{Case studies: Communicating in the field}

With over half of those employed on the HEED project outside of the United Kingdom, team members were dependent on digital communication to convey project aims, targets and desired outcomes to those working in the field. Berthille Kampire was employed as part of Practical Action's Rwanda team working with HEED's community mobilisers based at Gihembe refugee camp. She felt that researchers were not always sensitive to the difficulty's refugees face when they encounter new methods using technologies.

Conducting research in refugee camps isn't easy due to the fact that many platforms and systems are used. Researchers have to understand possibilities and limitations and develop accurate tools to have smart and informed conversations with teams, stakeholders, and suppliers, e.g., Informing researchers that taking pictures, you may need to ask permission at Kigali level, using recording equipment may not be agreed by everyone, some refugees don't know how to use a smartphone. Research[ers] need to work closely with people on the ground when developing questionnaires or developing interventions.

Berthille Kampire | Support Field Officer, Gihembe Camp

While in her role as the first point of contact for the camp stakeholders engaged in the HEED project, Berthille felt that researchers would benefit greatly by recognising her experiences as a resource.

Being the first energy implementer in the camps, the way we capture field observations, articulate and share them with the team is crucial for proper decision making. As a field officer in the camp, seeing, think, and hear different factors that can affect the project, I developed new ways of discussing with refugees. Our voice and our ways of thinking really matter a lot for the project achievements.

Ibid

As Berthille comments show, those working with refugee communities are often best placed to advise how to engage displaced people to support community co-designed energy interventions and ways of translating that into practical, affordable and culturally appropriate solutions.

Dr Jonathan Nixon, HEED co-investigator, found involvement in D4D and E4E community workshops give him a greater contextual understanding of designing energy interventions in the displacement setting before deployment. Discussing with Congolese refugees in Kigeme and Nyabiheke camp the energy interventions, he felt improved the process of design, installation, and maintenance of two off-grid solar-battery systems. Although Jonathan considerable expertise, experiences and skills in solar system engineering, being part of these conversations allowed Jonathan and his team to design micro-grid systems sized to cover what the community saw as meeting their immediate needs. 
As an energy system designer, one of the difficulties working in the displaced context is that refugees don't have many electronic devices that are common in most household settings. So, talking with them helped me make appropriate decisions about the capacity and sustainability of the micro-grid.

Dr Jonathan Nixon | HEED Co-Investigator, Coventry University

Co-designing with the community also saw HEED plan for micro-grids to have the capacity for growth in activities, which meant the interventions could be repurposed during the pandemic restrictions. So, there was sufficient power for the community hall at Nyabiheke to serve as a hospital waiting room during the COVID camp lockdowns in 2020. While in Kigeme refugee camp, in July 2020, students returning from the University of Kigali to the camp when the campus was closed used the sockets at the nurseries for remote online learning.

The domains of research, practice and policy are not discrete categories but are interconnected by complex social interactions with multiple actors. Impactful projects are usually those that communicate directly with communities on an ongoing basis and engage shared aims, concerns, and outcomes. The building of sustainable relationships between researchers, practitioners, energy suppliers, and communities will generate discourse coalitions that facilitate dialogue to improve actors' capabilities and capacities.

\section{Skills development recommendation 2}

\section{Increased opportunities: In what ways did HEED address gaps in skills that supported economic growth, greater employment and career progression?}

i. Adopt a skills-based approach to improve energy access in the displaced setting. The Comprehensive Refugee Response Framework (CRRF) aims for 'immediate and longerterm needs of refugees and host communities supporting them to become resilient and self-reliant' (Crawford \& O'Callaghan, 2019). At the same time, camp-based refugees are subject to structural barriers that limit economic opportunities, such as the right to work and the lack of access to funding on a national level. Similarly, one of the most difficult challenges in delivering safe, modern, and affordable energy in the displacement context is the sustainability of energy systems. Yet, living in unstable and fragile settings for protracted times limits long-term local initiatives. A skills-based approach to improve energy can not resolve the broader political and economic tensions around camp-based refugees. Instead, projects that include investment to provide training on new energy technologies could bring about the appropriate skills to support opportunities of self-reliance for displaced people. Long term, a skills-based approach to energy could see camp-based refugees and IDPs shift towards being 'prosumers', both users and producers of energy, which will benefit camp and host communities. ${ }^{4}$

4 Increasingly, prosumers - who both produce and use renewable energy are seen as future key players in delivering a more equal distributed and democratised energy future (see Brown et al, 2019. 
ii. Plan opportunities within the project for communities to gain skills during the design and production phases to support the sustainability of renewable energy interventions. A skills-based approach reflects a more market-based approach to energy provision at the field level. Framing energy solutions in the displacement setting as a potential market co-joins the energy needs, priorities, and aspirations of communities with the facilitation to produce a skills base to meet market demands. One approach is for energy projects to reject a single model of practice in favour of a range of approaches to developing skills, including what community assets can be drawn upon to promote local buy-in and support. Another approach is when partnering with private-sector agencies build-in training mechanisms that continue to support access to sustainable and affordable energy goods and services after as well as during the project.

\section{Case studies: Community mobilisers}

From 2018-2020, HEED employed nine camp-based refugees in Rwanda and two IDPs in Nepal as community mobilisers. The recruitment was conducted by Practical Action, with other humanitarian actors (such as Minema and UNHCR in Rwanda) participating in the interviews and selection process. The community mobilisers were directly supervised by Practical Action field workers. They were paid monthly through a mobile money system and received training on HEED energy interventions from local solar contractors.

\section{Community mobilisers roles and responsibilities}

- Communication and community engagement: Community mobilisers were instrumental in distributing information to inform the community about the installations, their purpose and benefits. They recruited participants for workshops, periodically collected assessment forms from survey participants and presented project updates during community meetings or gatherings.

- Security protocols: Community mobilisers were trained to implement security protocols in the event that the installed equipment was stolen or broken.

- Record keeping: Community mobilisers sent weekly checklists to the Practical Action HEED project manager, along with logbooks that collected data on the installation's usage, demographics of users and feedback. They were also responsible for battery replacement for solar energy installations.

Despite the initial disappointment that there were no applications from women in Rwanda for the role, the experience had generally been highly positive for those employed and in some cases, Evariste Muhire, Practical Action Support Field Officer, notes life changing:

People benefit from being empowered to make choices for themselves. Working with HEED has enabled community mobilisers to gain knowledge that unlocked them and opened doors for them. In the job market, they stand out because of the knowledge and experience they have.

Evariste Muhire | Support Field Officer, Nyabiheke Camp 
After the handover of the installations from HEED to the NGOs in the Rwandan camps, some of the community mobilisers went on to employment with the solar energy suppliers that installed HEED interventions. The suppliers gave them training, certification and tools to maintain and operate the solar systems for an additional twelve months.

Community mobilisers played a crucial role in the sustainability and security of the systems, which benefited the community at large. Part of their remit was to engage households living in close proximity in safeguarding the energy installations, which was so successful there were little to no theft or vandalism incidents to the installations. Evariste notes that: 'Sometimes the materials used had a problem that was solved not by the technician's physical presence but by talking to those on the ground (community mobilisers) and being told what to do and/or even solved remotely'. An unforeseen benefit of employing refugees and IDPs as community mobilisers was they played a crucial role in maintaining the interventions during the COVID-19 lockdowns when external technicians could not access the camps:

During COVID-19, I really saw how community mobilisers had furthered their skills. Sometimes the energy interventions had a problem, which usually would be resolved by sending in a technician. But when the camp was in lockdown by talking to those on the ground [community mobilisers], they would often resolve the issue themselves once told what to do if we couldn't solve them remotely.

Berthille Kampire | Support Field Officer, Gihembe Camp

Similarly, support field officer Theogene Ndatimana found that his skills developed while working on the HEED project, which also became relevant to other related energy research projects. As well as being the direct supervisor of the community mobilisers in Kigeme Camp, Rwanda, Theogene had key responsibilities for The Renewable Energy for Refugees (RE4R) project, a partnership between Practical Action, UNHCR, the UN Refugee Agency supported by the IKEA Foundation.

I really gained knowledge, skills and experience in relation to working with researchers on energy needs and possible solutions in humanitarian settings. I got to understand the energy need, access and usage for both electricity and cooking fuel in the camp through the installation of microgrid, provision of briquettes to families selected for the research and monitoring of energy use from the solar microgrid and use of cookstoves in Kigeme refugee camp. HEED project allowed me to work with refugees to understand their energy needs and serve as an informative observation of the RE4R project. ${ }^{5}$ In addition to data collected from the monitoring on the use of cookstove, I understood the issues with the type of cooking fuel and cookstove in place, which helped me expand my ideas onto RE4R intervention of renewable biomass for cooking in households.

\section{Theogene Ndatimana | Support Field Officer, Kigeme Camp}

5 The Renewable Energy for Refugees (RE4R) project facilitates finance, training, technology and expertise to improve access to renewable energy for homes, schools, health clinics and businesses. Improving the energy infrastructure RE4R seeks to help refugees and their host communities to move refugees from reliance on aid to economic independence so that refugees can 'thrive'. For more information, see Practical Action website. 


\section{Skills development 3}

\section{Life Experiences - How did involvement with the project alter peoples' perspective, practices and knowledge?}

i. Acknowledge how project involvement is transformative personally, as well as professional, for those working on the project. People who see work in terms of improving personal fulfilment through helping others, rather than only as a source of income or status-related, are more likely to report higher job satisfaction levels (Hearst, 2016). However, when documenting the impact of involvement in research projects, the focus is often on how those researched have engaged with demonstrate tangible, measurable outputs (Staley et al, 2017). Marginalising the emotional impact of research involvement fails to recognise the way the experience of working on a project can have an impact in profound and sometimes life-changing ways for individuals. Recognising how research projects enrich the teams personal and professional development acknowledges the importance of well-being both for the lives of those being researched and for team members.

ii. Recognise and record the teams 'learning journey' as an impact of the project. Integral to participation in a project is the constant process of discussing, practising, learning, researching and experimenting. These demands impact the well-being of researchers, project partners, and other project actors, especially when working with vulnerable communities and contexts. Identifying at an early stage how researchers acquire new skills and knowledge through involvement will lead to best practice around participation and empowerment, increase confidence when approaching future projects and opportunities, and foster an inclusive, mutually supportive working environment.

\section{Case studies: HEED partners}

One significant shift in practices resulting from being involved with the project was that some team members became more open to acting as conveners with displaced communities, meaning they chose to 'navigate a complex process' rather than 'having to find solutions to complex problems' (Van Hille et al, 2019). Milan Joshi, a technical field worker in Nepal, was responsible for co-ordinating the handover of the project's assets to the community, maintaining relationships with the local municipality and communication between the camp leaders, HEED and Practical Action. Although he had considerable knowledge about the international development sector, Milan found that working with displaced people developed new insights into the lived experience of energy poverty.

From my personal perspective, I was exposed to working in a humanitarian context which is something that I was not used to doing. I had a decade long experience in the development sector, but this engagement developed my skills in dealing with the displaced population, especially those in temporary settlements.

Milan Joshi | Technical field officer, Khalte, Nepal

Applying the understanding he had gained from his interactions with IDPs better prepared Milan to be guided by the community on the ability and resources they had to effect a rate of change, which at times might not match project expectations. 
The people in the HEED camp in Khalte had to start from scratch as they had not a single asset left due to them being displaced. This meant the entire foundations on livelihood and alternative income options were explored. And while this was not the core purpose of our assignment, engaging with these camp committees throughout was enriching as I was seen and consulted in these discussions as one of their own. This gave me a first-hand experience of categorising the needs of such a displaced population (like immediate and basic, medium for subsistence and long term for growth and resilience) and a logical step to bring them back to the normal economy, which is a long-long process.

Ibid

When collecting feedback from the community and their leaders regarding the systems' potential improvement, he gained a new understanding of the complexity of improving access to energy in the displaced setting. Thus, Milan found being open to community knowledge and experiences resulted in appropriate contextual solutions.

Photo: The Entrepreneur. Improved access to energy means entrepreneurial enterprises, like Gamini's shop, can communicate more effectively with suppliers (Khalte, Nepal).

Encouraging project partners and researchers to reflect on how involvement with the project has helped them acquire a broader range of skills is making them better equipped to move forward with other energy projects. Sandy Robinson, Scene's research manager, was involved in the HEED project as part of the Scene technical team, including developing the Renewable Energy Recommendation Tool (RERT). The RERT tool draws upon intelligent measurement that records the energy consumption of a wide range of energy systems and interventions in the displaced setting to ascertain best practice in providing sustainable, cost-effective and suitable forms of energy services in the displaced setting.

His role also focused on designing the HEED user interface boards and overseeing and delivering HEED workshops. Building on the success of seeing community co-design in action, he now leads several projects in Africa around renewable energy that adopted the same approach, including managing a project in Uganda to develop and test innovative precision irrigation systems' Resource Efficient Farming by Renewable Ugandan Irrigation Technology (REFRUIT). Involvement with the HEED project did not necessarily alter Sandy's commitment to community-led approaches to energy interventions. Rather, working on the project reinforced Sandy's motivation to continuously seek ethical best practice in energy-design interventions. Subsequently, he emphasises dialogue between himself and the communities to develop an inclusive, collective discourse around energy.

I feel strongly about supporting people to have a voice, whether that be helping UK communities negotiate with renewable energy developers or providing farmers with a means of understanding and engaging with new ideas and technologies. To me, the route to this is collective negotiation and action, leveraging the power of many voices to create a louder and stronger platform.

Sandy Robinson | Scene Research Manager 
Melania Tarquino, Practical Action HEED Project Manager, also reflected that recognising the value of 'soft skills' development, as well as the acquisition of 'hard skills', facilitates a sense of personally and professionally achievement. As a key member of the HEED Project Management Team, Melania was responsible for co-ordinating and exchanging information between Coventry University, Practical Action, and Scene. She oversaw both the operational project management in two countries and the delivery of energy interventions, including the recruitment, administration and training of field-based operatives.

Working on HEED allowed me to improve what you would call my hard skills- I learnt so much about budgeting and contract management, particularly negotiating complex staff changes and contracts. I became more proficient in my report writing and understanding the technical aspects of energy systems. But where I learnt the most was my soft skills - I gained confidence and felt more able to manage expectations around project delivery.

Melania Tarquino | Practical Action HEED Project Manager

Melania's role was central in generating and implementing employment opportunities for campbased Congolese refugees in Rwanda and IDPs in Nepal. As she navigated the expectations from a range of stakeholders, Melaina found that she became more confident and proficient at creating connections across organisational and geographic boundaries:

As I managed a range of stakeholders in three different countries, I found ways to communicate different cultural contexts, which has given me a new perspective on working with an international team. I learned that there are rarely 'quick fixes' to improving access to energy, but lasting change can be delivered given the right investment and continued support in improving skills, which in turn can offer improved life opportunities and chances in the lives of refugees. Although the project demanded a lot from me at times, I feel it has better prepared me to take the next stage in my career.

Melania Tarquino | Practical Action HEED Project Manager

In sharing the impact of involvement both professionally and personally of working on HEED, Melania feels she can make sense of and apply more effectively the learning she gained from the project. Collecting and documenting how researchers and partners responded to and experienced their time on a project provides a body of knowledge that can improve practice and nurture supportive work environments. It also promotes the notion that every person connected with the project has a valuable and valued contribution. 


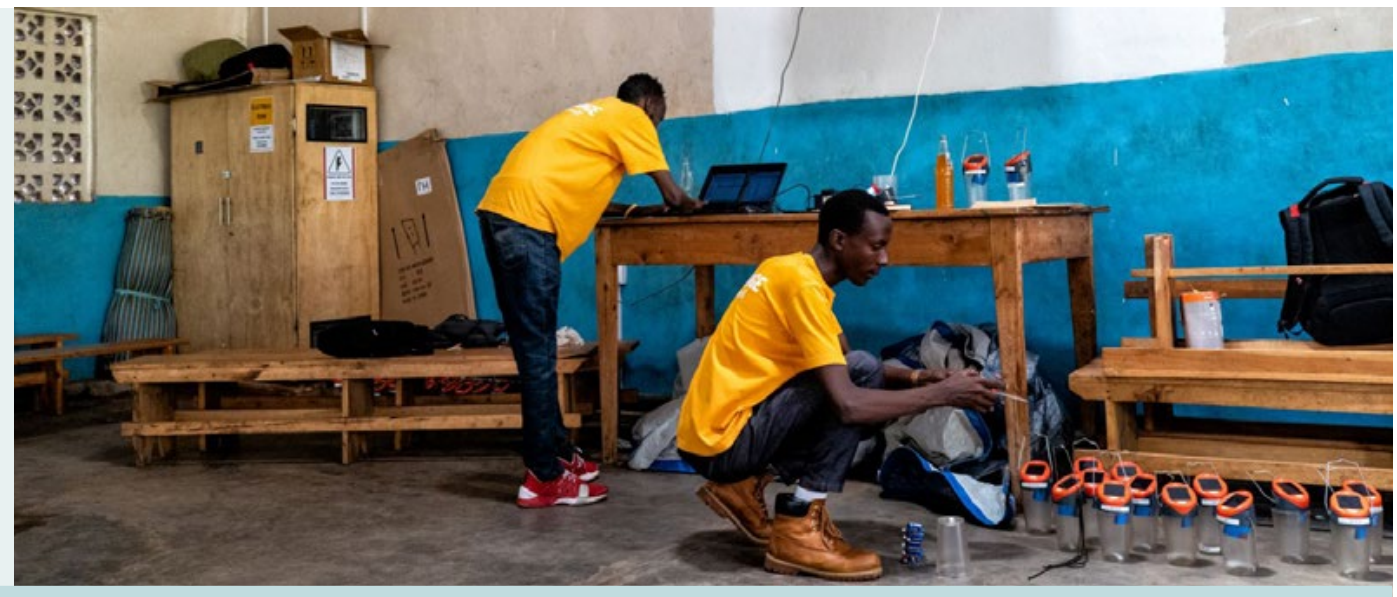

\section{Concluding reflections}

\section{How do you measure success?}

When documenting HEED's impact on developing skills, joint working and partnership development was evidently impactful and significant on many levels during the project lifetime. In addition, it has been recognised that the HEED designathon workshops, such as the D4Ds and E4Es, are a productive tool in bringing together camp leaders, communities and energy actors (Rosenberg-Jansen et al, 2019). Community co-design and energy design processes are opportunities for establishing community assets, aiding skills development and supporting selfdetermination.

In common with most projects, HEED impacts are a work in progress; therefore, the team is still identifying all the outcomes, significant changes, and the future will share the new findings. However, auditing the skills required by humanitarian engineering projects means moving beyond skills development equated only with qualifications and economic progression. Instead, we suggest that skills development includes how engagement with the project has made a difference for individuals, communities, organisations, and strategy, policy and practice. The recognition that professional and personal development, both formal and informal, gained during the project lifetime can be instrumental in promoting respect, inclusion and well-being for all involved in the research. Furthermore, skill development cannot be treated as an optional add-on to a project but needs to be embedded in a strategic vision to build lasting capacity and capability for project teams, partners and communities. 


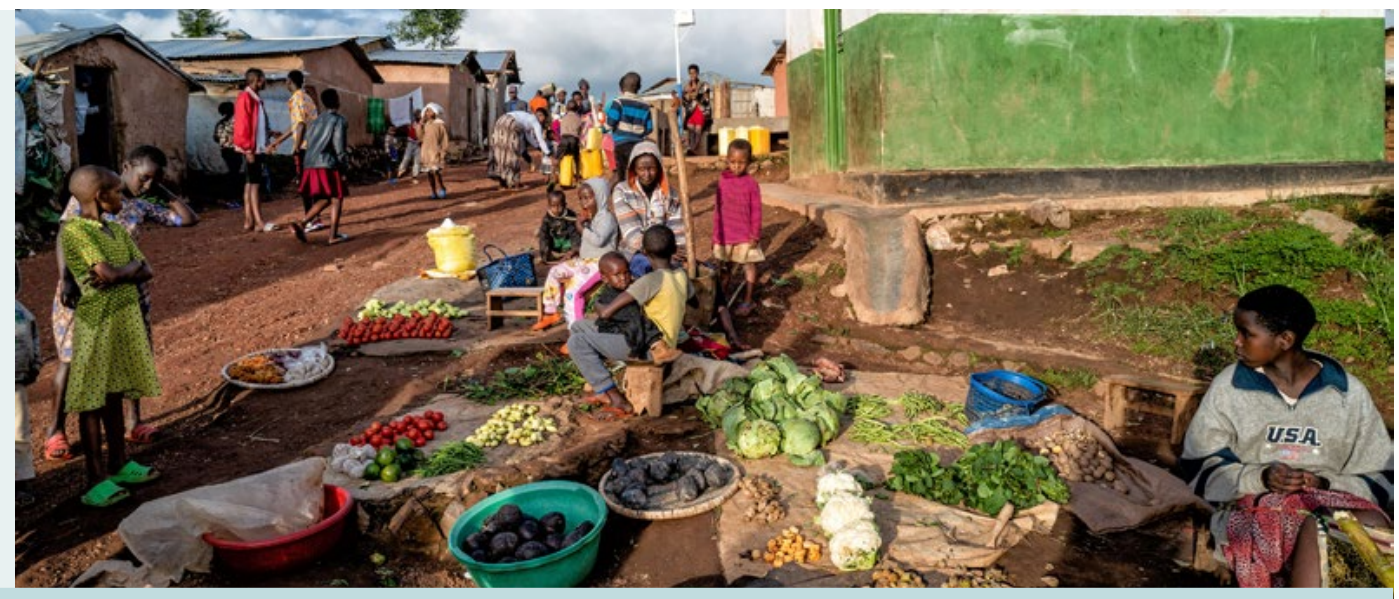

\section{HEED team and project partners}

\section{Coventry University}

The HEED project was led by Professor Elena Gaura, Professor of Pervasive Computing, with co-investigators, Professor Heaven Crawley, Professor of Migration, Centre of Trust, Peace and Social Relations and Dr Jonathan Nixon, Associate Head of School (Research), School of Mechanical, Aerospace and Automotive Engineering. The Coventry University team span several disciplines; engineering, data science, sociology, global development, and international relations and included, at various times, student internships, PhD candidates, early career, mid and established academics. The HEED project reflects Coventry University values, which actively supports innovative and ethical research to promote knowledge with societal application and academic excellence to effect change on a global platform.

\section{Practical Action}

Practical Action was HEED's delivery partner in the field in Rwanda and Nepal. Practical Action is committed to finding ways to provide renewable, locally sourced, sustainable energy solutions that can lift people out of poverty. In partnering with HEED, Practical Action sought to involve the community in having access to technologies that enabled them to meet their energy basic needs through safe, affordable, and environmentally ethical energy interventions. Practical Action was instrumental in recruiting staff in Rwanda and Nepal, engaging stakeholders, such as community leaders, camp field staff, and overseeing the delivery, maintenance and distribution of energy interventions. 


\section{Scene}

Scene is a social enterprise that focuses on strengthening communities through consultancy, research, and ICT products development. Scene works across renewable energy and 'energy access' sectors to develop systems that can lead to communities' ethical and economic empowerment. Scene oversaw the delivery of Microgrid User Interface workshops in Rwanda to understand displaced communities' lived experiences in relation to their energy needs. They were also responsible for developing technical outcomes for the HEED project such as the Data Portal, Renewable Energy Recommendations Tool (RERT tool) and the solar streetlights information boards

\section{Demographics}

In three years, the HEED project involved 109 people across three countries from seven organisations in various roles throughout the project cycle.

\begin{tabular}{|l|c|l|}
\hline Organisation & Employed & Roles \\
\hline Coventry University & 25 & Academics; interns; administrators \\
\hline Practical Action & 24 & $\begin{array}{l}\text { Technical field officer; Project Manager; Support } \\
\text { field officers; Senior project support, technical } \\
\text { advice and quality assurance; Senior in-country } \\
\text { support; Contracts and finance support staff; }\end{array}$ \\
\hline $\begin{array}{l}\text { HEED in camps (employed } \\
\text { refugees/IDPs) }\end{array}$ & 46 & $\begin{array}{l}\text { Enumerators; Security guards; Community } \\
\text { mobilisers }\end{array}$ \\
\hline Scene & 8 & \begin{tabular}{l} 
Project directors; managers; software designers \\
\hline Contractors
\end{tabular} \\
\hline
\end{tabular}
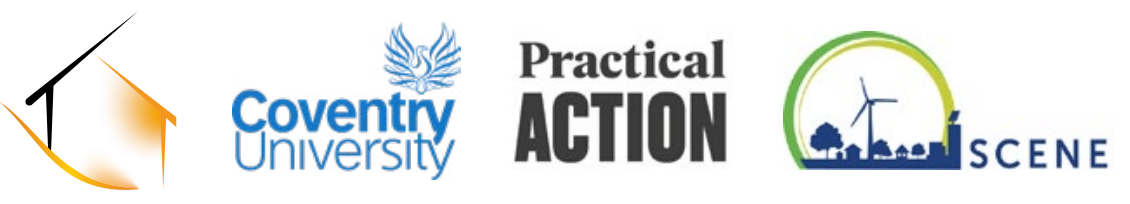


\section{References}

Alcoff, L. (2009). The problem of speaking for others. In: Voice in qualitative inquiry: Challenging conventional, interpretive, and critical conceptions in qualitative research. Jackson, A., and Mazzei, L. [eds] Oxfordshire: Routledge, 117-137.

Brown, D., Hall, S. \& Davis, M.E. (2019). Prosumers in the post subsidy era: an exploration of new prosumer business models in the UK. Energy Policy, 135: 110984. doi: 10.1016/j.enpol.2019.110984

Crawford, N., \& O'Callaghan, S. (2019). The Comprehensive Refugee Response Framework: responsibilitysharing and self-reliance in East Africa. London: Humanitarian Policy Group, Overseas Development Institute.

Demir, E. (2020). Improving energy access for displaced populations: An institutional analysis for the potential of community solar mini-grids in refugee camps. Unpublished Master thesis. Delft University of Technology.

Easton-Calabri, E. \& Omata, N. (2018). Panacea for the refugee crisis? Rethinking the promotion of 'selfreliance' for refugees. Third World Quarterly, 39 (8): 1458-1474. doi: 10.1080/01436597.2018.1458301

Hurst, A., Pearce, A., Erickson, C., Parish, S., Vesty, L., Schnidman, A., Garlinghouse, M. \& Pavela, A. (2016). Purpose at work, 2016 Global Report. Imperative and Linkedln.

Lehne, J., Blyth, W., Lahn, G., Bazilian, M., \& Grafham, O. (2016). Energy services for refugees and displaced people. Energy Strategy Reviews, 13-14: 134-146. doi: 10.1016/j.esr.2016.08.008

Lahn, G. \& Grafham, O. (2015). Heat, light and power for refugees saving lives, reducing costs. Chatham House Report for the Moving Energy Initiative. London: Royal Institute of International Affairs.

Rosenberg-Jansen, S., Tunge, T. \& Kayumba, T. (2019). Inclusive energy solutions in refugee camps. Nature Energy, 4 (12): 990-992. doi: 10.1038/s41560-019-0516-х

Rosenberg-Jansen, S. (2020). Rethinking energy economies for refugees. Oxford: Oxford Department of International Development, University of Oxford.

Staley, K., Abbey-Vital, I. \& Nolan, C. (2017). The impact of involvement on researchers: a learning experience. Research, Involvement and Engagement, 3 (20). doi: 10.1186/s40900-017-0071-1

Taplin, D., Clark, H., Collins, E., \& Colby, D. (2013). Theory of Change Technical Papers. A series of papers to support development of theories of change based on practice in the field. New York: ActKnowledge. p3.

UNHCR, 2017. UNHCR's Strategic Directions 2017-2021. Geneva: UN Refugee Agency.

Van Hille, I., de Bakker, F., Ferguson, J. \& Groenewegen, P. (2019). Navigating tensions in a cross-sector social partnership: How a convener drives change for sustainability. Corporate Social Responsibility and Environmental Management, 26 (2): 317-329. doi: 10.1002/csr.1684

Weiss, C.H. (1995). Nothing as practical as good theory: exploring theory-based evaluation for comprehensive community initiatives for children and families. In: Connell, J., Kubisch, A., Schorr, L. \& Weiss, C. (Eds.) New approaches to evaluating community initiatives: Concepts, methods and contexts. New York: Aspen Institute (65-92). 


\section{Humanitarian Engineering and Energy for Displacement (HEED)}

Since the introduction of the UNCHR global strategy on Safe Access to Fuels and Energy (SAFE) in 2014, humanitarian responses to refugees and internally displaced people (IDPs) have sought to deliver safe and sustainable energy provision. By focusing on the lived experiences of refugees and IDPs in Nepal and Rwanda to understand energy usage in refugee camps and settlements, the HEED project will develop, and contribute to, innovative responses which address demands for improved energy services.

Our research, led by key experts in the fields of engineering and social science, is looking for solutions that will provide crucial guidance on creative approaches and technologies to clean or fuel-efficient cookers, alternative and sustainable fuels, and solar-powered lighting, which will build the resilience of refugee communities.

\section{Our partners}

The HEED project, is led by an interdisciplinary team based at Coventry University, in partnership with the international development charity, Practical Action, and Scene Connect, a social enterprise strengthening communities through the development of ICT products.

\section{$\triangle$ Contact us}

www.heed-refugee.coventry.ac.uk

This research has been funded by the EPSRC Global Challenges Research Fund (Grant N EP/P029531/1).

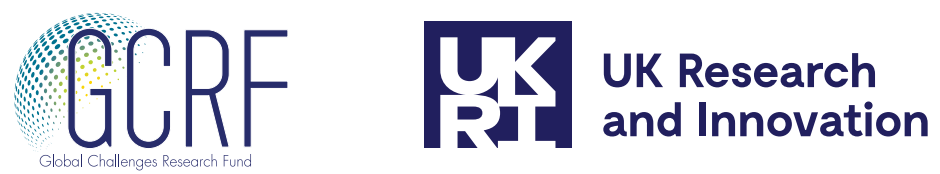

